\title{
Inhibitory effects of Gleditsia sinensis fruit extract on telomerase activity and oncogenic expression in human esophageal squamous cell carcinoma
}

\author{
WING K. TANG ${ }^{1}$, CHUNG H. CHUI ${ }^{1}$, SARWAT FATIMA ${ }^{1}$, STANTON H.L. KOK ${ }^{1}$, KAI C. PAK ${ }^{1}$, TIAN M. OU ${ }^{2}$, \\ KIN S. HUI ${ }^{1}$, MEI M. WONG ${ }^{1}$, JOHN WONG ${ }^{3}$, SIMON LAW ${ }^{3}$, S.W. TSAO ${ }^{4}$, KING Y. LAM ${ }^{5}$, PHILIP S.L. BEH ${ }^{6}$, \\ GOPESH SRIVASTAVA ${ }^{6}$, KWOK P. HO ${ }^{1}$, ALBERT S.C. CHAN ${ }^{1,7}$ and JOHNNY C.O. TANG ${ }^{1,6,7}$ \\ ${ }^{1}$ Lo Ka Chung Centre for Natural Anti-Cancer Drug Development, Central Laboratory of the Institute of Molecular \\ Technology for Drug Discovery and Synthesis, Department of Applied Biology and Chemical Technology, \\ The Hong Kong Polytechnic University, Hong Kong; ${ }^{2}$ School of Pharmaceutical Sciences, Sun Yat-sen \\ University, Guangzhou; ${ }^{3}$ Department of Surgery, ${ }^{4}$ Department of Anatomy, The University of Hong Kong, \\ Hong Kong, P.R. China; ${ }^{5}$ School of Medicine, Griffith University, Queensland, Australia; \\ ${ }^{6}$ Department of Pathology, The University of Hong Kong, Hong Kong; ${ }^{7}$ State Key Laboratory \\ of Chinese Medicine and Molecular Pharmacology, Shenzhen, P.R. China
}

Received October 10, 2006; Accepted January 22, 2007

\begin{abstract}
Previous studies have shown that the anomalous fruit extract of Gleditsia sinensis (GSE) exhibited apoptotic properties in various solid and non-solid tumors in vitro. However, the inhibitory actions of GSE on oncogenic expression and telomerase activity in esophageal squamous cell carcinoma (ESCC) have not been studied before. In the present study, the anti-cancer effects of GSE were demonstrated in three ESCC cell lines (HKESC-1, HKESC-2 and SLMT-1) by MTS and anchorage-independent clongenicity assays, expression studies on oncogenes at 11q13 (CCND1, INT2, FGF4 and EMS1) and real-time quantitative telomeric repeat amplification protocol assay to show the inhibitory effect of GSE on telomerase in ESCC. The means of $\mathrm{MTS}_{50}$ of GSE for the ESCC cell lines and non-tumor NIH 3T3 cells were 21 and $163 \mu \mathrm{g} / \mathrm{ml}$ respectively. The anchorage-independent clongenicity assay showed that SLMT-1 cells lost their colony-forming potential which was dose-dependent to GSE. Moreover, GSE demonstrated dosedependent suppression on the expression of INT2, EMS1 and $F G F 4$, and inhibition of telomerase activity in the ESCC cell
\end{abstract}

Correspondence to: Dr Johnny Cheuk-on Tang, Department of Applied Biology and Chemical Technology, The Hong Kong Polytechnic University, Hung Hom, Hong Kong, P.R. China E-mail: bccotang@inet.polyu.edu.hk

Key words: esophageal squamous cell carcinoma, telomerase, oncogenic expression lines. Our overall results thus provide the first evidence that the anti-cancer effects of GSE on ESCC involve the suppression of oncogenic expression and inhibition of telomerase activity. Our findings also offer a new opportunity for the future development of GSE as a novel anti-cancer agent for ESCC and possibly for other cancers.

\section{Introduction}

Gleditsia sinensis $(G S)$ is a traditional Chinese medicine that is widely distributed in Chinese mainland (1). The anomalous fruit of $G S$ produced by old or injured plants is rich in saponin and has promising therapeutic actions (2). The Gleditsia sinensis extract (GSE) was also demonstrated by our group to have anti-cancer properties on both solid and non-solid tumors in vitro $(1,3)$ acting through different mechanisms (4-8). Thus, a further understanding of the anti-cancer actions of GSE on specific targets will yield great benefits for exploring it as a novel anti-cancer agent.

Moreover, previous results of comparative genomic hybridization $(\mathrm{CGH})$ analysis showed that a high level of gene amplification at chromosome 11q13 was frequently found in ESCC cases (9). Within this amplified region, there are 4 candidate oncogenes, namely CCND1, INT2, FGF4 and EMS1. Both CCNDI and EMS1 were shown to be overexpressed in various tumors (10). It was well documented that the targeted suppression of expression of these oncogenes could yield great benefits as anti-cancer mechanisms that yield new approaches for the development of anti-cancer drugs. Examples include a downregulation of the expression of CCND1 in human Burkitt's lymphoma Daudi cells in vitro after exposure to deguelin, which is an isolated natural plant product and used as a lung cancer chemopreventive agent (11). 
Telomerase is a ribonucleoprotein enzyme complex that adds telomeric DNA repeats (TTAGGG) to chromosome ends to compensate for the losses that occur with each round of DNA replication (12). Telomerase activity is not detected in most human somatic tissues (13). However, a high level of telomerase is shown in $85-90 \%$ of human cancers (14), including tumors of esophageal squamous cells as well as in their preneoplasia lesions (15). Telomerase is thought to be involved in the long-term proliferation and immortalization of tumors, and the by-passing of apoptosis (16). The aim of the present study was to further investigate the anti-cancer effects of GSE, in terms of suppressing the expression of the ESCC-related oncogenes located at the 11q13 region and the telomerase activity on the selected ESCC cell lines of Hong Kong Chinese origin. Our findings will provide a better understanding of the targeted anti-cancer mechanisms of GSE on ESCC and possibly on other cancers in the future.

\section{Materials and methods}

ESCC cell lines. Four ESCC cell lines of Hong Kong Chinese origin, including SLMT-1 (17), HKESC-1 (18), HKESC-2 and HKESC-3 (19), were kindly provided by Professor Gopesh Srivastava, Department of Pathology, The University of Hong Kong and maintained as described (20). The mouse fibroblast cell line NIH $3 \mathrm{~T} 3$ was purchased from the American Type Culture Collection (ATCC) and cultured as described (20). NE1 cells which are non-tumor esophageal epithelial cells (21) were kindly provided by Professor George S.W. Tsao, Department of Anatomy, The University of Hong Kong and cultured as described (20).

RT-PCR analysis. The extraction of total RNA and reverse transcription were performed as previously described by our group (20). The expression levels of CCND1, INT2, EMS1 and FGF4 in the NE1 cells, and the ESCC cell lines with or without GSE or CDDP treatments were analyzed by multiplex RT-PCR as previously described (20). Two $\mu \mathrm{g}$ of cDNA produced by reverse transcription from the RNA was amplified as previously described by using the specific PCR primers of CCND1, INT2, EMS1 and FGF4 and specific glyceraldehyde-3-phosphate dehydrogenase (GAPDH) gene primers acting as an internal control for normalizing the cDNA quantity. The primers for CCND1 (22) were: CCND1-F 5'-CTG CTC CTG GTG AAC AAG CTC-3' and CCND1-R 5'-CTC TGG AGA GGA AGC GTG TG-3'; the primers for INT2 (23) were: INT2-F 5'-CAG AAG CAG AGC CCG GAT AA-3' and INT2-R 5'-ACG CCA AGA TGT CGC CAG GA-3'; the primers for EMS1 (24) were: EMS1-F 5'TCC CCT GAT GCC CAG GTC-3' and EMS1-R 5'-TCC CAA TCC AGA GAC CCG-3'; and the primers for $F G F 4$ (25) were: FGF4-F 5'-ACC TTG GTG CAC TTT CTT CG$3^{\prime}$ and FGF4-R 5'-CTC CAC TGT TGC ACC AGA AA-3' and the primers of GAPDH were: GAPDH-1 5'-TGA AGG TCG GAG TCA ACG GAT TTG GT-3' and GAPDH-2 5'CAT GTG GGC CAT GAG GTC CAC CAC-3' (Clontech). The PCR products were then electrophoresed in a $2 \%$ agarose gel and visualized under UV. The intensities of the PCR products were measured by the densitometric analysis using the Quantity One program (Bio-Rad). The intensities of the target PCR product were normalized against the GAPDH expression in each sample. The relative expression level of the target gene was expressed by the formula: (target gene/ GAPDH, for ESCC cell line with or without drug treatment)/ (target gene/GAPDH, for NE1 or untreated control) (26). The level was regarded as overexpression when the ratio was $>1.2$; a ratio between 0.8 and 1.2 was regarded as no change; and a ratio $<0.8$ was regarded as underexpression of the gene (27).

Preparation of GSE. The dried fruit of Gleditsia sinensis was ground into powder in a mortar and the GSE was prepared as previously described by our group using absolute ethanol (6).

MTS cytotoxicity and soft agar assays. The cytotoxic effects of GSE and CDDP on the 3 ESCC cell lines and NIH 3T3 cells were investigated by using the MTS activity assay as previously described (5) using CellTiter96 ${ }^{\circledR}$ AQueous One Solution cell proliferation assay (Promega). The soft agar assay for the SLMT-1 cells was performed as previously described with the bottom layer containing different concentrations of GSE, ranging from $0,6.25,12.5,25,50$ and $100 \mu \mathrm{g} / \mathrm{ml}(1)$.

Real-time quantitative telomeric repeat amplification protocol (Q-TRAP) assay. The Q-TRAP assay was performed by using Quantitative Telomerase Detection (QTD) kit (US Biomax, Inc), in which about $2.5 \times 10^{4}$ cells of each pellet treated or untreated with GSE or cisplatin (CDDP, Sigma) were lysed according to the manual's instructions. Three $\mu \mathrm{g}$ of total protein in the cell extracts was added to the SYBRGreen PCR master mix and the PCR qualified water to give a final volume of $25 \mu 1$, and then programmed in the real-time PCR detection system using real-time thermal cycler (SmartCycler ${ }^{\circledR}$ Technology, Cepheid). The reactions were performed at $25^{\circ} \mathrm{C}$ for $20 \mathrm{~min}$, followed by incubation at $95^{\circ} \mathrm{C}$ for $10 \mathrm{~min}$, and were amplified for 38 cycles of denaturation at $95^{\circ} \mathrm{C}$ for $30 \mathrm{sec}$, annealing at $60^{\circ} \mathrm{C}$ for $30 \mathrm{sec}$ and extension at $72^{\circ} \mathrm{C}$ for $30 \mathrm{sec}$. Four controls were included in the assays; 3 sets of telomerase negative controls: a) lysis buffer; b) heat-inactivated cell extracts; and c) $5 \mu \mathrm{M}$ of telomerase inhibitor (MST-312, Calbiochem) (13), as well as d) a telomerase-positive control of non-inactivated HKESC-1 cell extract (18). The statistical significance of the difference in the means of relative telomerase activity after the treatments of different GSE concentrations was determined by the ANOVA test (single factor) and Paired t-test (one-tailed), requiring $\mathrm{P}<0.05$ (95\% confidence level) for statistical significance.

\section{Results}

MTS growth inhibition assay. Results of MTS assay revealed that the means of $\mathrm{MTS}_{50}$ of GSE for the ESCC cell lines (SLMT-1, HKESC-1 and HKESC-2) and non-tumor NIH 3T3 cells were 21 and $163 \mu \mathrm{g} / \mathrm{ml}$ respectively after $48 \mathrm{~h}$ of GSE treatment (Fig. 1). This suggested that GSE may be useful for treating ESCC while causing low cytotoxicity on non-tumor cells. The mean of MTS $_{50}$ of CDDP for the ESCC cell lines was $12.3 \mu \mathrm{g} / \mathrm{ml}$ and that for the NIH $3 \mathrm{~T} 3$ cells was $12 \mu \mathrm{g} / \mathrm{ml}$ 

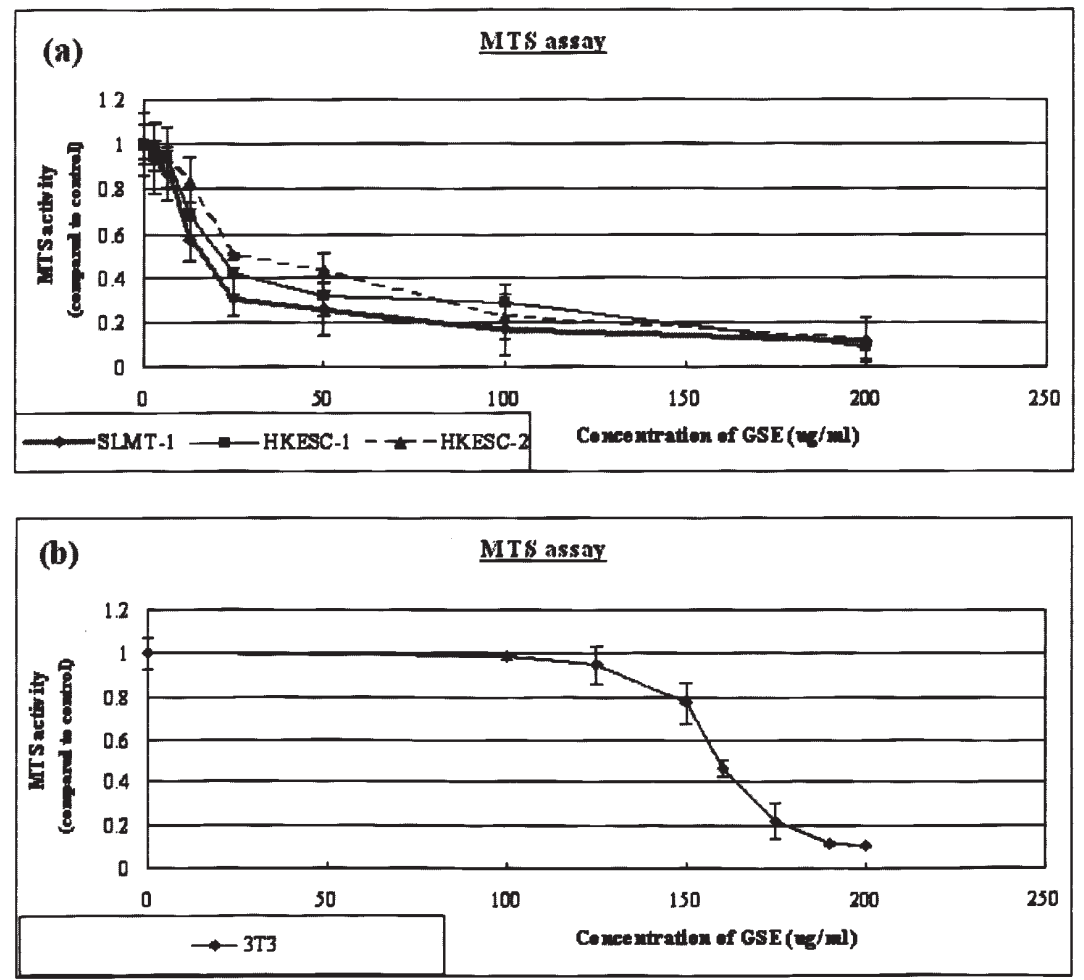

Figure 1. MTS activity assay showing the anti-cancer actions of GSE at the concentrations of $0,3.125,6.25,12.5,25,50,100$ and $200 \mu \mathrm{g} / \mathrm{ml}$ on (a) ESCC cell lines and (b) NIH 3 T3 cells after $48 \mathrm{~h}$ of GSE incubation. Results are representative of three independent experiments.
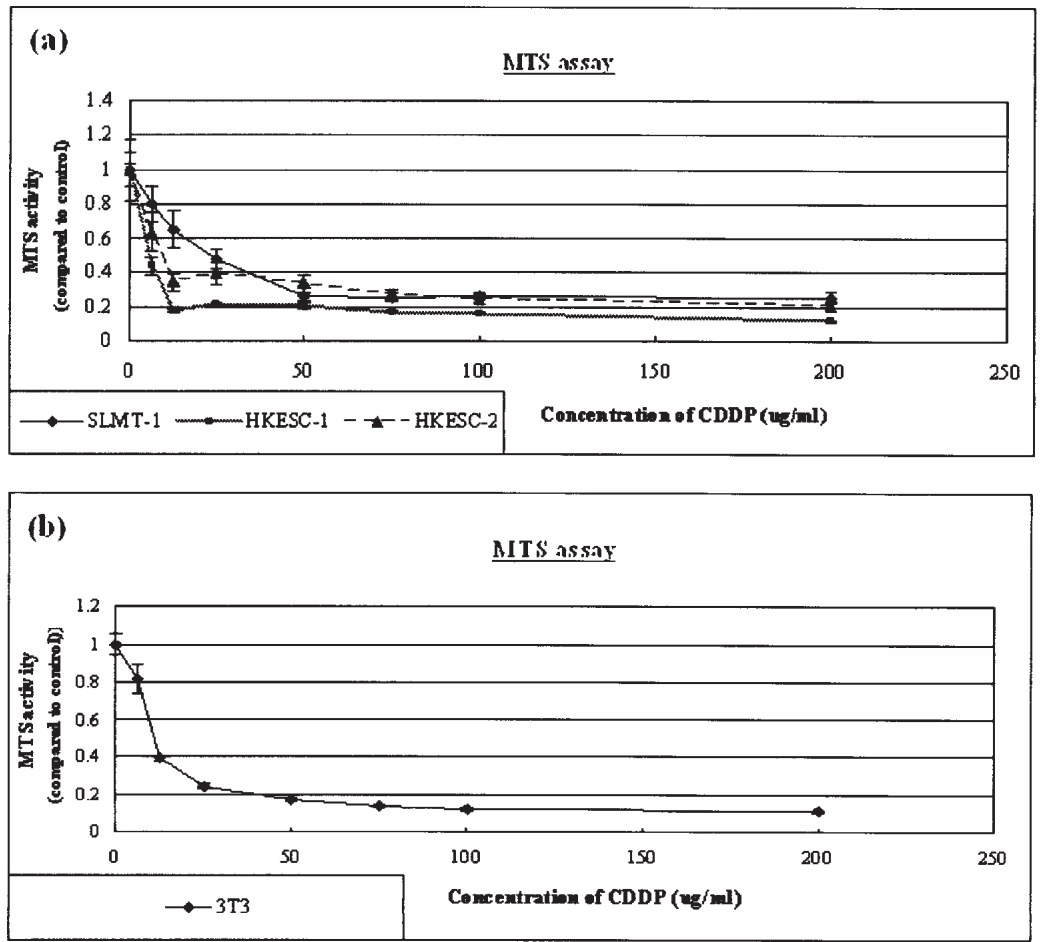

Figure 2. MTS activity assay showing the anti-cancer actions of CDDP at the concentrations of $0,6.25,12.5,25,50,100$ and $200 \mu \mathrm{g} / \mathrm{ml}$ on (a) ESCC cell lines and (b) NIH 3 T3 cells after 48 h of CDDP incubation. Results are representative of three independent experiments.

(Fig. 2). The overall MTS assay showed that both GSE and CDDP contributed dose- and time-dependent growth inhibitory effects on ESCC and non-tumor NIH 3T3 cell lines.
Soft agar assay. Among the 3 ESCC cell lines, only SLMT-1 cells could form colonies on soft agar. Thus, SLMT-1 was chosen for this part of the study. The anchorage-independent clongenicity assay showed that SLMT-1 cells lost their 


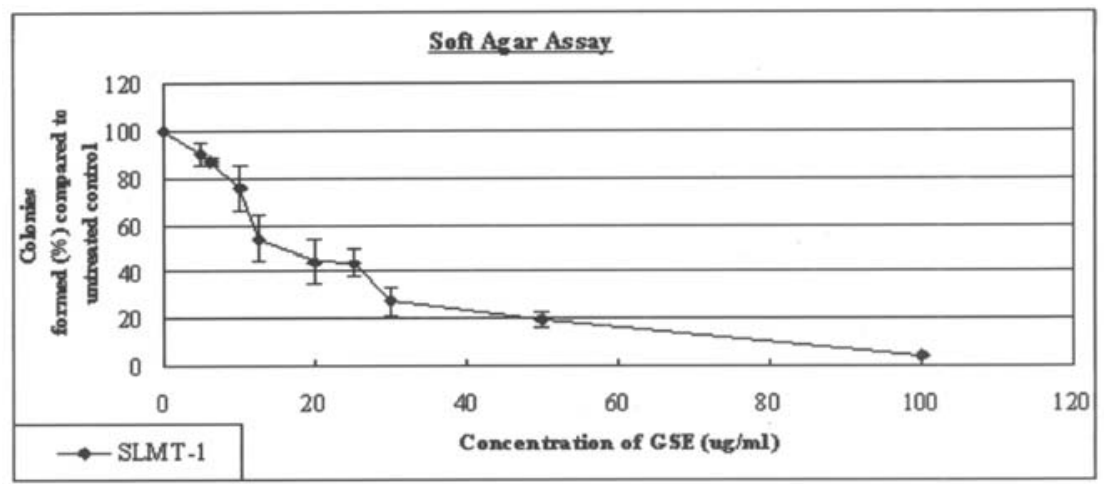

Figure 3. Inhibition of colony formation of SLMT-1 cells after GSE action. The assay was performed to establish the action of GSE at the concentrations of 0, $5,6.25,10,15,20,25,30,50$ and $100 \mu \mathrm{g} / \mathrm{ml}$ on the inhibition of colony formation (\%) of SLMT-1 cells. Results are representative of three independent experiments.
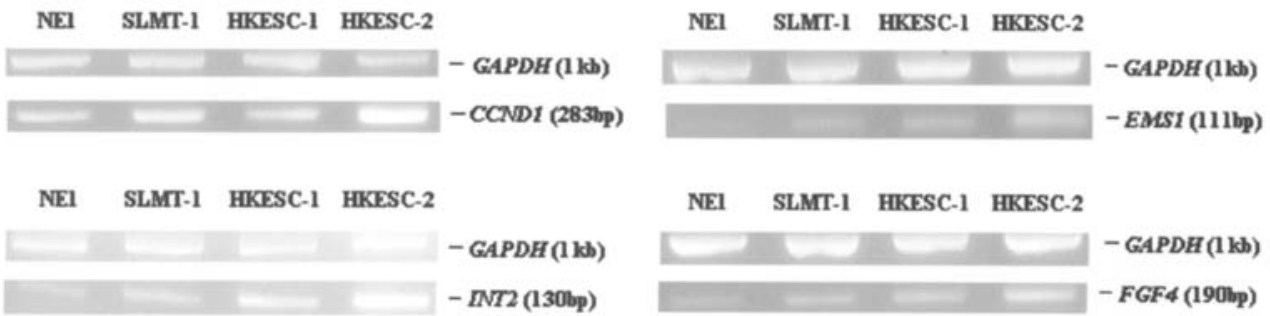

Figure 4. Studies of $11 \mathrm{q} 13$ oncogene expression in three ESCC cell lines. Without GSE and CDDP treatments, the expression levels of EMS1, INT2 and FGF4 were elevated in all ESCC cell lines (HKESC-1, HKESC-2 and SLMT-1) when compared with the non-tumor epithelial cell line (NE1). However, only both SLMT-1 and HKESC-2 cells overexpressed CCND1, while HKESC-1 cells showed no change in CCND1 expression. GAPDH expression was used as an internal control.

colony-forming potential which was dose-dependent to GSE (Fig. 3). The colonies were reduced by $50 \%$ when the dose of GSE was increased to $20 \mu \mathrm{g} / \mathrm{ml}$, and $<5 \%$ of colonies formed once it reached $100 \mu \mathrm{g} / \mathrm{ml}$.

Effects of GSE on oncogenic expression in ESCC studied by multiplex RT-PCR analysis. The effects of GSE on the expression of 4 oncogenes in 11q13 (CCND1, EMS1, INT2 and FGF4) were studied in the 3 ESCC cell lines (SLMT-1, HKESC-1 and HKESC-2) when compared with NE1 cells. Without GSE and CDDP treatments, the expression levels of EMS1, INT2 and FGF4 were elevated in all (3/3) ESCC cell lines (Fig. 4). However, only both SLMT-1 and HKESC-2 cells overexpressed $C C N D 1$, while HKESC-1 cells showed no change in CCND1 expression (Fig. 4). After GSE treatment, the CCND1 level was not changed significantly with an increased GSE dose in all 3 ESCC cell lines (HKESC-1, HKESC-2 and SLMT-1). In contrast, they all showed underexpression of FGF4 when the GSE dose was increased to the range of 25-100 $\mu \mathrm{g} / \mathrm{ml}$ (Fig. 5). Moreover, INT2 and EMS1 expression levels were reduced in SLMT-1 and HKESC-2 respectively once the GSE dose reached $100 \mu \mathrm{g} / \mathrm{ml}$ (Fig. 5). The effect of CDDP on these 4 oncogenes was also included and regarded as a control in the expression study, since $15 \mu \mathrm{g} / \mathrm{ml}$ of CDDP induced a 50\% reduction in MTS activity in all 3 ESCC cell lines; hence, this concentration of CDDP was used to treated the ESCC cells prior to oncogenic expression studies. Approximately $15 \mu \mathrm{g} / \mathrm{ml}$ of CDDP was found to cause underexpression of EMS1 in all ESCC cell lines (3/3); it also led to underexpression of INT2 and FGF4 in both SLMT-1 and HKESC-2 cells as well. CDDP-treated HKESC-1 cells showed an overexpression of CCND1, in contrast to the results of the CDDP-treated SLMT-1 and HKESC-2 cells which showed no change in expression and underexpression of $C C N D 1$, respectively (Fig. 5). Since the GSE was extracted by absolute ethanol, its effect on the oncogenic expression could also be examined in the assay, which showed that absolute ethanol did not change the expression of the 4 selected oncogenes in $11 \mathrm{q} 13$ in all of the 3 ESCC cell lines (Fig. 5). The overall results of the expression study demonstrated that GSE exerted a dosedependent inhibitory effect on the expression of the oncogenes in 11q13, including INT2, EMS1 and FGF4, while CDDP downregulated all the selected oncogenes located on 11q13 in the ESCC cell lines.

Effects of GSE on telomerase activities in ESCC. The results of the Q-TRAP assay indicated that telomerase activities were detectable in all of the extracts of the ESCC cell lines without drug treatment (Table I and Fig. 6). Dose-dependent telomerase inhibition was detected after $48 \mathrm{~h}$ of treatment using GSE and CDDP. Relative telomerase activity (RTA) was reduced by $\sim 96,50$ and $76 \%$ in the cells of SLMT-1, HKESC-1 and HKESC-2, respectively when $12.5 \mu \mathrm{g} / \mathrm{ml}$ of GSE was applied to the cultured cells prior to the Q-TRAP assay, and the RTA was low or even undetectable (repressed 
(A)
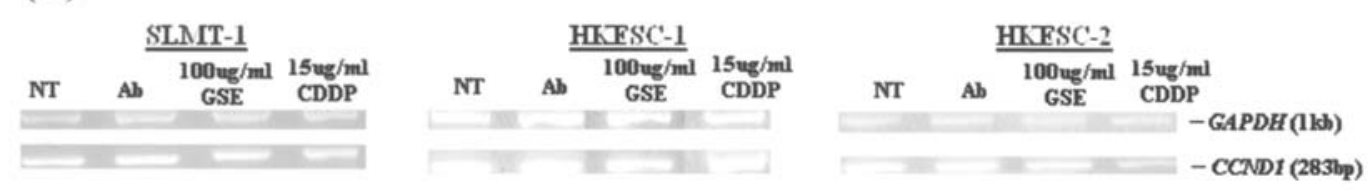

(B)
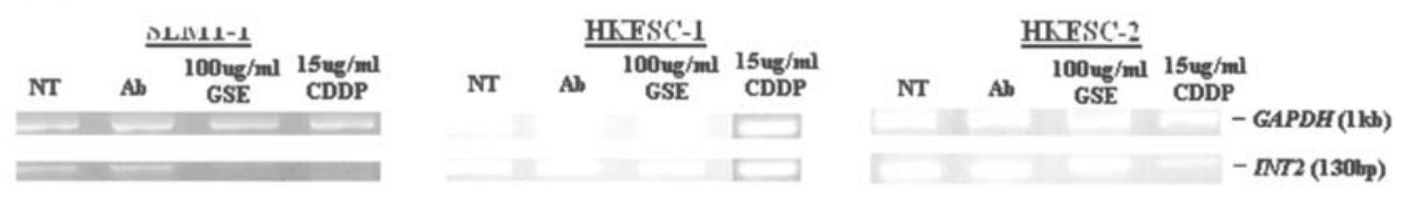

(C)
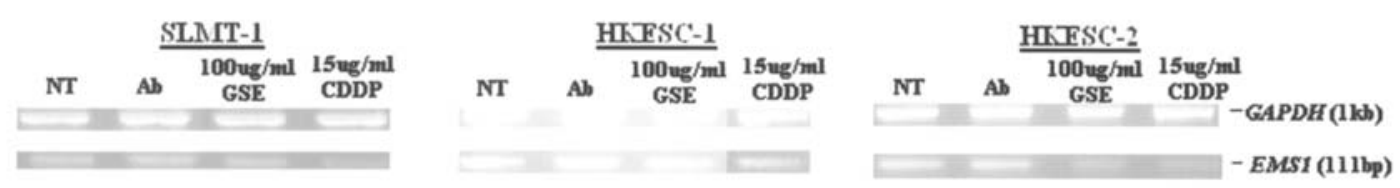

(D)
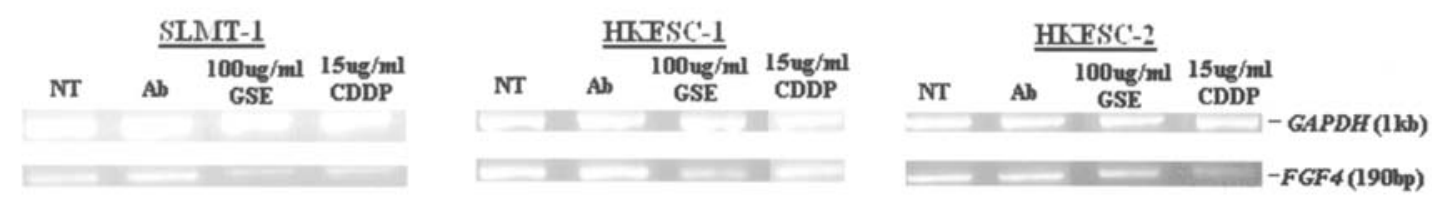

Figure 5. Selected results of the oncogenic expression in the three ESCC cell lines. The alterations in the expression level of (A) CCND1, (B) INT2, (C) EMS1 and (D) FGF4 in ESCC cell lines (HKESC-1, HKESC-2 and SLMT-1) after GSE or CDDP treatments were compared to the untreated controls. GSE downregulated the expression of INT2, EMS1 and FGF4, while CDDP downregulated all of the selected oncogenes located on 11q13 in the ESCC cell lines. NT, untreated control; Ab, absolute ethanol treated ESCC cells. GAPDH expression was used as an internal control.

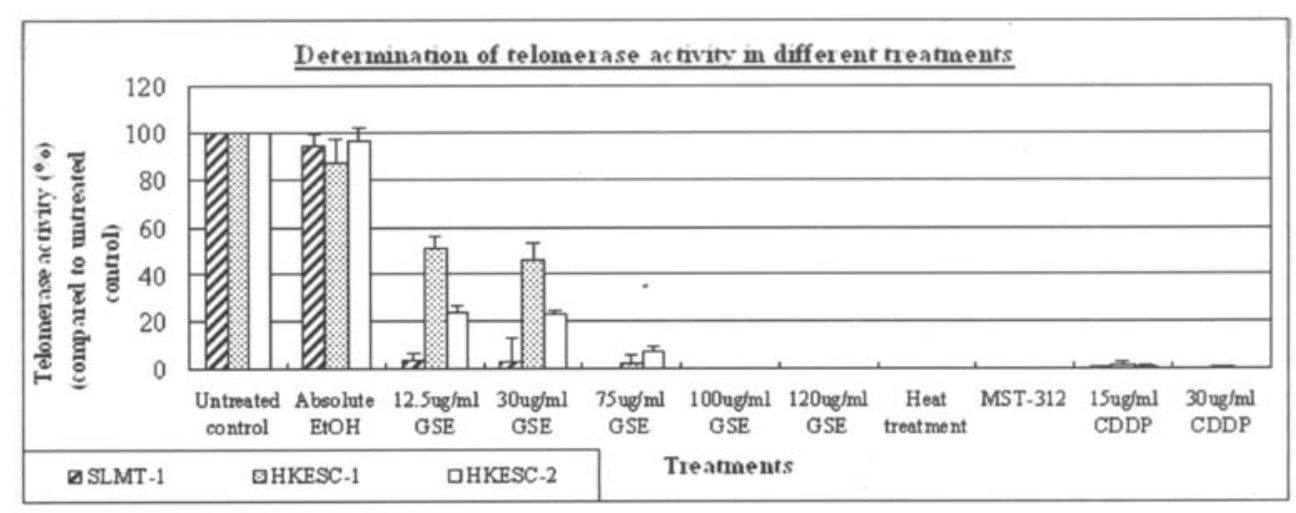

Figure 6. Determination of telomerase activity in different treatments by the Q-TRAP assay. Without any drug treatment, the telomerase activities were detectable in all ESCC cell extracts (SLMT-1, HKESC-1 and HKESC-2). There was no significant difference in the mean of RTA between the cells treated with absolute ethanol and the untreated control (t-test, $\mathrm{P}=0.0569)$. Telomerase activity was undetected in SLMT-1 cells when $\geq 75 \mu \mathrm{g} / \mathrm{ml}$ of $\mathrm{GSE}$ was added, while $\sim 100 \mu \mathrm{g} / \mathrm{ml}$ or more of GSE was needed to give a similar response in both HKESC-1 and HKESC- 2 cells. The RTA values were approximately zero in both the heat-inactivated and telomerase inhibitor (MST-312)-supplemented samples. Results were expressed with mean \pm SD from triplicate experiments. RTA, relative telomerase activity; untreated control, ESCC cell extracts (SLMT-1, HKESC-1 and HKESC-2).

by $98 \%$ ) when CDDP reached $\geq 15 \mu \mathrm{g} / \mathrm{ml}$ reducing the $\mathrm{MTS}_{50}$ activity by $>50 \%$ in the ESCC cell lines. The telomerase activity was undetectable in SLMT- 1 cells when $\geq 75 \mu \mathrm{g} / \mathrm{ml}$ of GSE was added, while $\sim 100 \mu \mathrm{g} / \mathrm{ml}$ or more of GSE was required to give a similar response in both the HKESC-1 and HKESC-2 cells. Since the RTA values were approximately zero in the negative controls, including both heat-inactivated and telomerase inhibitor MST-312-supplemented samples, this indicated that the specificity of product formation in the Q-TRAP assay was attributed to the heat-sensitive telomerase activity. Since the GSE was extracted by absolute ethanol, the inhibitory effect of absolute ethanol on telomerase activities was examined in the assay showing no significant difference in the means of RTA between the cells 
Table I. Studies of GSE and CDDP actions on telomerase activities in different drug-treated samples compared with untreated control. ${ }^{\mathrm{a}}$

Sample treatments ESCC cell lines

\begin{tabular}{|c|c|c|c|c|c|}
\hline SLMT-1 & HKESC-1 & HKESC-2 & SLMT-1 & HKESC-1 & HKESC-2 \\
\hline \multicolumn{3}{|c|}{$\begin{array}{c}\text { Mean number of TSR molecules } \\
\text { (molecules/reaction) }\end{array}$} & $\begin{array}{r}\text { Telc } \\
\text { ur } \\
\text { RTA }=\end{array}$ & $\begin{array}{l}\text { activity con } \\
\text { control (RT) } \\
\left.\mathrm{M}_{\mathrm{H}}\right) /\left(\mathrm{M}_{\mathrm{C}}-\mathrm{N}\right.\end{array}$ & \\
\hline
\end{tabular}

\begin{tabular}{|c|c|c|c|c|c|c|}
\hline Untreated control & $58468 \pm 6303$ & $1505 \pm 49$ & $1244 \pm 69$ & $100 \pm 10.78$ & $100 \pm 9.90$ & $100 \pm 5.55$ \\
\hline Absolute ethanol & $55227 \pm 4044$ & $1317 \pm 228$ & $1198 \pm 149$ & $94.45 \pm 6.92$ & $87.51 \pm 15.15$ & $96.30 \pm 11.98$ \\
\hline GSE $12.5 \mu \mathrm{g} / \mathrm{ml}$ & $2119 \pm 448$ & $766 \pm 190$ & $291 \pm 55$ & $3.62 \pm 0.77$ & $50.90 \pm 12.62$ & $23.39 \pm 4.42$ \\
\hline GSE $30 \mu \mathrm{g} / \mathrm{ml}$ & $1719 \pm 555$ & $690 \pm 97$ & $282 \pm 70$ & $2.94 \pm 0.95$ & $45.86 \pm 6.45$ & $22.67 \pm 5.63$ \\
\hline GSE $75 \mu \mathrm{g} / \mathrm{ml}$ & $0 \pm 0$ & $36 \pm 5$ & $89 \pm 19$ & $0 \pm 0$ & $2.39 \pm 0.33$ & $7.15 \pm 1.53$ \\
\hline GSE $100 \mu \mathrm{g} / \mathrm{ml}$ & $0 \pm 0$ & $0 \pm 0$ & $0 \pm 0$ & $0 \pm 0$ & $0 \pm 0$ & $0 \pm 0$ \\
\hline Heat treatment & $0 \pm 0$ & $0 \pm 0$ & $0 \pm 0$ & $0 \pm 0$ & $0 \pm 0$ & $0 \pm 0$ \\
\hline MST-312 inhibitor & $0 \pm 0$ & $0 \pm 0$ & $0 \pm 0$ & $0 \pm 0$ & $0 \pm 0$ & $0 \pm 0$ \\
\hline CDDP $15 \mu \mathrm{g} / \mathrm{ml}$ & $335 \pm 44$ & $22 \pm 3$ & $6 \pm 0$ & $0.57 \pm 0.08$ & $1.46 \pm 0.20$ & $0.48 \pm 0$ \\
\hline CDDP $30 \mu \mathrm{g} / \mathrm{ml}$ & $27 \pm 3$ & $6 \pm 1$ & $0 \pm 0$ & $0.05 \pm 0.01$ & $0.40 \pm 0.07$ & $0 \pm 0$ \\
\hline
\end{tabular}

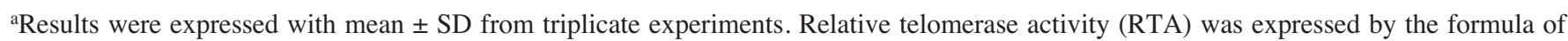
$\mathrm{RTA}=\left(\mathrm{M}_{\mathrm{S}}-\mathrm{M}_{\mathrm{H}}\right) /\left(\mathrm{M}_{\mathrm{C}}-\mathrm{M}_{\mathrm{H}}\right) \times 100 \% ; \mathrm{M}_{\mathrm{S}}$, mean number of TSR molecules of sample; $\mathrm{M}_{\mathrm{C}}$, mean number of TSR molecules of the untreated control; $\mathrm{M}_{\mathrm{H}}$, mean of TSR concentration of the heat-treated sample.

treated with absolute ethanol and the untreated control (t-test, $\mathrm{P}=0.0569$ ). The overall results of the Q-TRAP assay showed that highly significant differences in the means of RTA were observed in the three ESCC cell lines, with reduction in telomerase activity when the concentration of GSE was increased, compared with the untreated control (ANOVA test, $\left.\mathrm{P}=1.08 \times 10^{-5}\right)$.

\section{Discussion}

The anti-cancer effects of GSE on the ESCC cell lines were first evaluated by MTS assay, and the results showed that a 48-h incubation was the minimal time required for GSE to bring the cytotoxic effects to the ESCC cell lines. The mean GSE concentration of $21 \mu \mathrm{g} / \mathrm{ml}$ was required to inhibit $50 \%$ of MTS activity in the ESCC cell lines (SLMT-1, HKESC-1 and HKESC-2) after $48 \mathrm{~h}$ of GSE incubation, while that of the positive control CDDP was $12.3 \mu \mathrm{g} / \mathrm{ml}$. This suggested that GSE, similar to a widely used anti-cancer drug, CDDP, could exhibit inhibitory effects on the growth of ESCC cells in vitro. Most importantly, the non-tumor NIH $3 \mathrm{~T} 3$ mouse fibroblasts demonstrated much more resistance to GSE (mean $\mathrm{MTS}_{50}=163 \mu \mathrm{g} / \mathrm{ml}$ ) than CDDP (mean $\mathrm{MTS}_{50}=12 \mu \mathrm{g}$ / $\mathrm{ml}$ ), together with the previous observation that the normal peripheral blood lymphocytes could withstand a relatively high toxicity concentration, which was $\sim 38-43 \mu \mathrm{g} / \mathrm{ml}$ of GSE (1). This implies that GSE may have a selective anti-cancer action on cancer cells and it may be a potential chemotherapeutic agent for ESCC.

Recent studies have indicated that telomerase expression is associated with cell immortalization and tumorigenesis (28) which suggests that telomerase is an attractive target for cancer therapy. The possibility of GSE or CDDP in inhibiting telomerase activity was investigated by the QTRAP assay. Our results indicated that GSE demonstrated a dose-dependent repression on telomerase activity in SLMT-1, HKESC-1 and HKESC-2 cells, and telomerase activity in ESCC cells was undetected once GSE reached $100 \mu \mathrm{g} / \mathrm{ml}$ when compared to the untreated controls after $48 \mathrm{~h}$ of GSE incubation. Similarly, CDDP also exhibited a dose-dependent inhibition on telomere lengthening in the ESCC cell lines, and the level of telomerase was repressed by $\sim 98 \%$ at $15 \mu \mathrm{g} /$ $\mathrm{ml}$ of CDDP relative to the cells without treatment in the QTRAP assay. Hence, our results suggested that both CDDP and GSE may exert anti-cancer effects on the ESCC cell lines by repressing telomerase activity. The action of CDDP on telomerase inhibition was suggested by Ishibashi and Lippard (12), who found that a substantial reduction in telomere length followed by apoptosis was shown in HeLa cells after CDDP treatment (12). In the present study, $\sim 10-20$ $\mu \mathrm{g} / \mathrm{ml}$ of CDDP induced cytotoxic effects as well as suppressed telomerase activity in the telomerase-positive ESCC cell lines (SLMT-1, HKESC-1 and HKESC-2). Telomerase activity is a biomarker of cell proliferation since it is present in highly proliferative normal tissue in vivo, including hemopoietic cells and the oral mucosa, as well as in the immortalized cell lines and in most tumors, including ESCC, because of their high proliferative ability (29). Thus, any repression of telomerase activity would be unfavorable to cell proliferation and might contribute to apoptosis. In the present study, the results of the Q-TRAP assay suggested that GSE may be a potential telomerase inhibitor to human ESCC exhibiting a concentration-dependency to GSE which exerts cytotoxicity on human ESCC cell lines in MTS assay. Hence, 
our results proposed that GSE may cause growth inhibition on these GSE-treated ESCC cells, and this may correlate to substantial telomere reduction resulting from telomerase suppression.

Soft agar assay can be used to measure the sensitivity of human tumors to anti-cancer agents (3). Results of this assay revealed that SLMT-1 cells were sensitive to GSE which reduced their ability to grow as colonies in semi-solid media. Hence, this implicated that GSE might alter the transformed phenotype and abnormal growth characteristic as well as reduce the selectable growth advantage of SLMT-1 cells by suppressing their potential for anchorage-independent growth. Our present results of soft agar assay indicated that GSE might be a potential anti-cancer agent as it could inhibit the anchorage-independent growth of ESCC cells which was a key feature of ESCC tumor cells.

DNA amplification is a common mechanism for oncogene overexpression since it is assumed that the amplified DNA may include some critical genes whose overexpression provides a selective force for tumor development (30). An amplification at $11 \mathrm{q} 13$ is considered to have a relation with metastasis to the lymph nodes and may have an important role to play during the malignant progression in tumors (31). Four oncogenes located in $11 \mathrm{q} 13$, were found to be associated with various human tumors; for instance, CCND1 and EMS1 were shown to be overexpressed in all carcinomas with 11q13 amplification (32). Cyclin D1 (CCND1) encodes a cell-cycle regulatory protein of the G1/S phase checkpoint (33). Amplification and overexpression of CCND1 were reported as prognostic markers associated with metastasis to the lymph nodes and distal organs of ESCC (33). The protein of EMS1 was proposed to function as a signal transmitter between cell-matrix contact sites (34). An overexpression of EMS1 might affect the adhesive properties and metastasis of human carcinomas (34). Both INT2 (35) and FGF4 (32) belong to the basic fibroblast growth factor (FGF) gene family (30).

In the present study, the multiplex RT-PCR analysis demonstrated that GSE suppressed the expression of the oncogenes EMS1, INT2 and FGF4 at 11q13 which may be important for neoplastic transformation and tumor progression. A similar example includes epigallocatechin-3gallate (EGCG) which is one of the green tea polyphenolic compounds that has demonstrated anti-carcinogenic activities in various human cancers, including tumors of the stomach, esophagus, colon and lung (36). The anti-tumor effects of EGCG have been reported to be mediated by apoptosis, in which proteins of $b c l-X_{L}$ and proliferating cell nuclear antigen $(P C N A)$ are important in regulating EGCG-dependent apoptosis (36). A significant downregulation of $b c l-X_{L}$ and $P C N A$ resulting from 48 -h post-EGCG treatments were involved in inducing apoptosis in ovarian cancer cells (36). These findings suggest that both EGCG and the existing antitumor drugs, including vinblastine, etoposide, Ara-C and nocodazole, function through modulation of the expression levels of oncogenes, tumor-suppressor genes, and the genes related to metastasis and apoptosis.

Our overall results showed that GSE having a cytotoxic effect on the human ESCC cell lines exhibits dose-dependent inhibitory effects on telomerase activity, the expression of
INT2, FGF4 and EMS1, and the colony-forming potential of SLMT-1 cells. Our data implies that GSE exerts its anticancer effects through modulating the oncogenic expression and telomerase activity. Further effort is ongoing to elucidate the molecular mechanisms of GSE and the actions of its active components for use in cancer therapy.

\section{Acknowledgements}

We acknowledge the donation of Mr. Lo K.C. for setting up the Lo Ka Chung Centre for Natural Anti-Cancer Drug Development and for supporting the research described in this report. Chui C.H. is supported by the post of 'Research Fellow' from the project of 'Catalytic asymmetric synthesis of bioactive derivatives and the investigation of their anti-cancer activities' kindly offered by Professor Chan A.S.C. under the Areas of Excellence Scheme established by the University Grants Committee of the Hong Kong Special Administrative Region, P.R. China (project no. AoE/P-10/01). This project is also supported by the Niche Area Fund of the Hong Kong Polytechnic University (Project no. 1-BB8P). This research also forms part of the M.Phil study of Tang W.K.

\section{References}

1. Chow LCM, Tang JCO, Teo ITN, Chui CH, Lau FY, Leung TWT, Cheng G, Wong RSM, Wong ILK, Tsang KMS, Tan WQ, Zhao YZ, Lai KB, Lam WH, Guo DA and Chan ASC: Antiproliferative activity of the extract of Gleditsia sinensis fruit on human solid tumour cell lines. Chemotherapy 48: 303-308, 2002.

2. Zhong L, Li P, Han J, Qu G and Guo D: Structure-activity relationships of saponins from Gleditsia sinensis in cytotoxicity and induction of apoptosis. Planta Med 70: 797-802, 2004.

3. Chow LMC, Chui CH, Tang JCO, Teo ITN, Lau FY, Cheng GYM, Wong RSM, Leung TWT, Lai KB, Yau MYC, Guo D and Chan ASC: Gleditsia sinensis fruit extract is a potential chemotherapeutic agent in chronic and acute myelogenous leukemia. Oncol Rep 10: 1601-1607, 2003.

4. Chow LMC, Chui CH, Tang JCO, Lau FY, Yau MYC, Cheng GYM, Wong RSM, Lai PBS, Leung TWT, Teo ITN, Cheung F, Guo D and Chan ASC: Anti-angiogenic potential of Gleditsia sinensis fruit extract. Int J Mol Med 12: 269-273, 2003.

5. Teo ITN, Tang JCO, Chui CH, Cheng GYM, Yau MYC, Lau FY, Wong RSM, Leung TWT, Cheung F, Ho KP, Cheng CH and Chan ASC: Superoxide anion is involved in the early apoptosis mediated by Gleditsia sinensis fruit extract. Int J Mol Med 13: 909-913, 2004.

6. Chui CH, Tang JCO, Lau FY, Teo ITN, Yau MYC, Wong RSM, Cheng GYM, Ho SKW, Leung TWT, Hui KS and Wong MM: Gleditsia sinensis fruit extract induced growth inhibition involves basic fibroblast growth factor and nitric oxide. Int $\mathbf{J}$ Mol Med 13: 169-173, 2004.

7. Chui CH, Lau DFY, Chan ASC, Cheng GYM, Wong RSM, Lai KB, Kok SHL, Au Yeung TTL, Teo ITN, Yau MYC, Cheung F, Cheng $\mathrm{CH}$ and Tang JCO: Gleditsia sinensis fruit extract-induced apoptosis involves changes of reactive oxygen species level, mitochondrial membrane depolarization and caspase 3 activation. Int J Mol Med 15: 539-543, 2005.

8. Cheung F, Chui CH, Chan ASC, Lau FY, Cheng GYM, Wong RSM, Kok SHL, Teo ITN, Cheng CH and Tang JCO: Inhibition of proteasome activity in Gleditsia sinensis fruit extract-mediated apoptosis on human carcinoma cells. Int J Mol Med 16: 925-929, 2005.

9. Kwong D, Lam A, Guan X, Law S, Tai A, Wong J and Sham J: Chromosomal aberrations in esophageal squamous cell carcinoma among Chinese: gain of $12 \mathrm{p}$ predicts poor prognosis after surgery. Hum Pathol 35: 309-316, 2004.

10. Rodrigo JP, Garcia LA, Ramos S, Lazo PS and Suarez C: EMS1 gene amplification correlates with poor prognosis in squamous cell carcinomas of the head and neck. Clin Cancer Res 6: 3177-3182, 2000 . 
11. Liu HL, Chen Y, Cui GH, Wu QL and Jing HE: Regulating expressions of cyclin D1, pRB, and anti-cancer effects of deguelin on human Burkitt's lymphoma Daudi cells in vitro. Acta Pharm Sin 26: 873-880, 2005

12. Ishibashi T and Lippard SJ: Telomere loss in cells treated with cisplatin. Proc Natl Acad Sci USA 95: 4219-4223, 1998.

13. Seimiya H, Muramatsu Y, Ohishi T and Tsuruo T: Tankyrase 1 as a target for telomere-directed molecular cancer therapeutics. Cancer Cell 7: 25-37, 2005.

14. Quante M, Heeg S, Von Werder A, Goessel G, Fulda C, Doebele M, Nakagawa H, Beijersbergen R, Blum HE and Opitz OG: Differential transcriptional regulation of human telomerase in a cellular model representing important genetic alterations in esophageal squamous carcinogenesis. Carcinogenesis 26: 1879-1889, 2005.

15. Li C, Wu MY, Liang YR and Wu XY: Correlation between expression of human telomerase subunits and telomerase activity in esophageal squamous cell carcinoma. World J Gastroenterol 9: 2395-2399, 2003.

16. Seimiya H, Oh-hara T, Suzuki T, Naasani I, Shimazaki T, Tsuchiya $\mathrm{K}$ and Tsuruo $\mathrm{T}$ : Telomere shortening and growth inhibition of human cancer cells by novel synthetic telomerase inhibitors MST-312, MST-295, and MST-199. Mol Cancer Ther 1: $657-665,2002$.

17. Tang JCO, Wan TSK, Wong N, Pang E, Lam KY, Law SY, Chow LMC, Ma ESK, Chan LC, Wong J and Sarivastava G: Establishment and characterization of a new xenograft-derived human esophageal squamous cell carcinoma cell line SLMT-1 of Chinese origin. Cancer Genet Cytogenet 124: 36-41, 2001.

18. Hu YC, Lam KY, Wan TSK, Fang WG, Ma ESK, Chan LC and Srivastava G: Establishment and characterization of HKESC-1, a new cancer cell line from human esophageal squamous cell carcinoma. Cancer Genet Cytogenet 118: 112-120, 2000.

19. Hu YC, Lam KY, Law SY, Wan TSK, Ma ESK, Kwong YL, Chan LC, Wong J and Srivastava G: Establishment, characterization, karyotyping, and comparative genome hybridization analysis of HKESC-2 and HKESC-3: two newly established human esophageal squamous cell carcinoma cell lines. Cancer Genet Cytogenet 135: 120-127, 2002.

20. Fatima S, Chui CH, Tang WK, Hui KS, Au HW, Li WY, Wong MM, Cheung F, Tsao SW, Lam KY, Beh BSL, Wong J, Law S, Srivastava G, Ho KP, Chan ASC and Tang JCO: Transforming capacity of two novel genes $J S-1$ and $J S$ - 2 located in chromosome $5 \mathrm{p}$ and their overexpression in human esophageal squamous cell carcinoma. Int J Mol Med 17: 159-170, 2006.

21. Zhang H, Jin YS, Chen XH, Jin C, Law S, Tsao SW and Kwong YL: Cytogenetic aberrations in immortalization of esophageal epithelial cells. Cancer Genet Cytogenet 165: 25-35, 2006.

22. Akervall J, Borg A, Dictor M, Jin C, Jin YS, Tanner M, Isola J, Mertens F and Wennerberg J: Chromosomal translocations involving $11 \mathrm{q} 13$ contribute to cyclin $D 1$ overexpression in squamous cell carcinoma of the head and neck. Int J Oncol 20: 45-52, 2002.

23. Schwartz S Jr, Caceres C, Morote J, De Torres I, Rodriguez-Vallejo JM, Gonzalez J and Reventos J: Over-expression of epidermal growth factor receptor and c-erbB2/neu but not of int-2 genes in benign prostatic hyperplasia by means of semi-quantitative PCR. Int J Cancer 76: 464-467, 1998.
24. Yuan BZ, Zhou X, Zimonjic DB, Durkin ME and Popescu NC: Amplification and overexpression of the EMS1 oncogene, a possible prognostic marker, in human hepatocellular carcinoma. J Mol Diagn 5: 48-53, 2003.

25. Morini M, Astigiano S, Mora M, Ricotta C, Ferrari N, Mantero S, Levi G, Rossini M and Barbieri Q: Hyperplasia and impaired involution in the mammary gland of transgenic mice expressing human FGF4. Oncogene 19: 6007-6014, 2000.

26. Miyazono F, Metzger R, Warnecke-Eberz U, Baldus SE, Brabender J, Bollschweiler E, Doerfler W, Mueller RP, Dienes HP, Aikou T, Hoelscher AH and Schneider PM: Quantitative cerbB-2 but not c-erbB-1 mRNA expression is a promising marker to predict minor histopathologic response to neoadjuvant radiochemotherapy in oesophageal cancer. Br J Cancer 91: 666-672, 2004

27. Zhou C, Liu S, Zhou X, Xue L, Quan L, Lu N, Zhang G, Bai J, Wang Y, Liu Z, Zhan Q, Zhu H and Xu N: Overexpression of human pituitary tumor transforming gene $(h P T T G)$ is regulated by $\beta$-catenin/TCF pathway in human esophageal squamous cell carcinoma. Int J Cancer 113: 891-898, 2005.

28. Szatmari I and Aradi J: Telomeric repeat amplification, without shortening or lengthening of the telomerase products: a method to analyze the processivity of telomerase enzyme. Nucleic Acids Res 29: (2 e3), 2001.

29. Belair CD, Yeager TR, Lopez PM and Reznikoff CA Telomerase activity: A biomarker of cell proliferation, not malignant transformation. Proc Natl Acad Sci USA 94: 13677-13682, 1997

30. Kitagawa Y, Ueda M, Ando M, Shinozawa Y, Shimizu N and Abe O: Significance of int-2/hst-1 coamplification as a prognostic factor in patients with esophageal squamous carcinoma. Cancer Res 51: 1504-1508, 1991.

31. Mori M, Tokino T, Yanagisawa A, Kanamori M, Kato Y and Nakamura Y: Association between chromosome 11q13 amplification and prognosis of patients with oesophageal carcinomas. Eur J Cancer 28A: 755-757, 1992.

32. Schuuring E: The involvement of the chromosome 11q13 region in human malignancies: cyclin D1 and EMS1 are two new candidate oncogenes- a review. Gene 159: 83-86, 1995.

33. Takeuchi H, Ozawa S, Ando N, Kitagawa Y, Ueda M and Kitajima M: Cell-cycle regulators and the Ki-67 labeling index can predict the response to chemoradiotherapy and the survival of patients with locally advanced squamous cell carcinoma of the esophagus. Ann Surg Oncol 10: 792-800, 2003.

34. Zaharieva BM, Simon R, Diener PA, Ackermann D, Maurer R, Alund G, Knonagel H, Rist M, Wilber K, Hering F, Schonenberger A, Flury R, Jager P, Fehr JL, Mihatsch MJ, Gasser T, Sauter G and Toncheva DI: High-throughput tissue microarray analysis of $11 \mathrm{q} 13$ gene amplification (CCND1, $F G F 3, F G F 4, E M S 1)$ in urinary bladder cancer. J Pathol 201: 603-608, 2003

35. Huang YQ, Li JJ, Moscatelli D, Basilico C, Nicolaides A, Zhang WG, Poiesz BJ and Friedman-Kien AE: Expression of int-2 oncogene in Kaposi's sarcoma lesions. J Clin Invest 91: 1191-1197, 1993.

36. Huh SW, Bae SM, Kim YW, Lee JM, Namkoong SE, Lee IP, Kim SH, Kim CK and Ahn WS: Anticancer effects of (-)epigallocatechin-3-gallate on ovarian carcinoma cell lines. Gynecol Oncol 94: 760-768, 2004. 